\title{
Combined Density Functional Theory and Monte Carlo Analysis of Monomolecular Cracking of Light Alkanes Over H-ZSM-5
}

\author{
Diana C. Tranca, ${ }^{\dagger}$ Niels Hansen, ${ }^{\dagger}$ Joseph A. Swisher, $^{\ddagger}$ Berend Smit, $^{\ddagger}$ and Frerich J. Keil ${ }^{\dagger, *}$ \\ ${ }^{\dagger}$ Department of Chemical Engineering, Hamburg University of Technology, D-21073 Hamburg, Germany \\ ${ }^{\ddagger}$ Department of Chemical and Biomolecular Engineering, University of California, Berkeley, California 94720-1462, United States
}

\section{Supporting Information}

ABSTRACT: Density functional calculations applying periodic boundary conditions have been performed to investigate adsorption and cracking of light alkanes $\left(\mathrm{C}_{3}-\mathrm{C}_{6}\right)$ on zeolite H-ZSM-5. Intrinsic energy barriers were obtained from singlepoint calculations by applying the revised form of the $\mathrm{PBE}$ functional (RPBE) to structures optimized on the PBE potential energy surface. Dispersion interactions were accounted for by adding a damped dispersion term to the PBE energies. The dependence of the adsorption enthalpy on the carbon number is in agreement with experimental observation. From intrinsic energy barriers, intrinsic rate coefficients were calculated by means of transition state theory. The dependence of the intrinsic enthalpy and entropy of

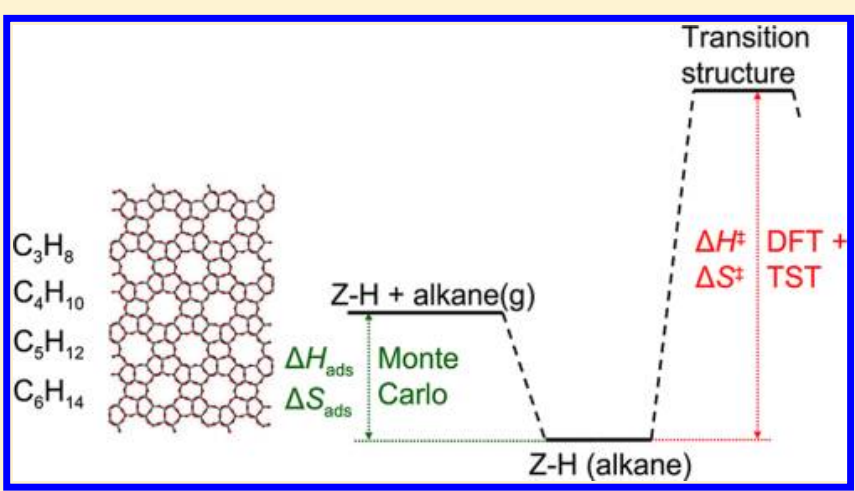
activation on the carbon number is discussed and compared to experimental observations. Transition path sampling was employed to unravel qualitatively the reaction mechanism for cracking of butane. Monte Carlo simulations in the canonical ensemble were conducted to estimate the temperature dependence of the adsorption enthalpy and entropy of propane to $n$ hexane. These quantities are not constant, as is often assumed in the interpretation of experimental data but become less negative with increasing temperature. It is shown how the selection of adsorption parameters influences the extraction of intrinsic rate parameters from experimental rate data. Based on the present analysis, an alternative partitioning of the experimentally accessible apparent entropy of activation into contributions from adsorption and intrinsic reaction is proposed.

\section{INTRODUCTION}

Zeolitic materials are being extensively employed in petroleum refining, petrochemicals production and pollution control, to catalyze a variety of reactions such as alkylation, aromatization, and isomerization of hydrocarbons. ${ }^{1-6}$ They exhibit both Brønsted and Lewis acidic properties. ${ }^{7}$ Basic zeolites have generated interest because of their selectivity in catalysis and their adsorption properties. ${ }^{7}$ The cracking of alkanes at Brønsted acid centers in zeolites is a reaction of major importance in the production of fuels from crude oil. The primary sources of propylene have been steam cracking (as a byproduct) and fluid catalytic cracking (FCC) units. Currently, about $30 \%$ of the world's propylene is supplied by FCC operations, $60-65 \%$ is coproduced from steam cracking, and the remaining is produced on-purpose using metathesis or propane dehydrogenation. ${ }^{8}$

For understanding the details of catalytic reactions, quantum chemical calculations, in particular those based on density functional theory (DFT) combined with statistical thermodynamics and transition state theory have been employed successfully over the past few years. ${ }^{9-13}$ Previous studies on $n$-alkane cracking in zeolites have mainly been conducted on small cluster models of the active site, ${ }^{14-23}$ leading to several artifacts such as a dependence of the intrinsic energy barrier on the size of the computational model, which makes conclusions about the degree of convergence difficult. Also, especially for larger alkanes, steric effects caused by the confinement within the zeolite pores are not well captured by small cluster models. Moreover, the long-range crystal potential is not well represented suggesting that it would be best to employ periodic boundary conditions. Note that in some recent work, cluster models in the context of QM/QM and QM/ $\mathrm{MM}$ approaches were used successfully to calculate accurate adsorption energies and energy barriers for hydrocarbon conversion reactions on zeolites. ${ }^{24,25}$ Calculations using periodic boundary conditions are of increasing interest in the study of zeolite catalyzed reactions ${ }^{26-29}$ and are feasible as long as the size of the adsorbate molecules is small compared to the dimensions of the simulation cell such that interactions with periodic images can be kept small. Previous periodic DFT calculations for propane cracking on ZSM-5 showed that the intrinsic entropy of activation was more negative $(-68.1 \mathrm{~J} /(\mathrm{mol}$ $\mathrm{K})$ ) compared to cluster calculations $(-34.9 \mathrm{~J} /(\mathrm{mol} \mathrm{K})){ }^{9}$ In a recent periodic DFT study reported by Bučko et al. ${ }^{30}$ a similar

Received: July 31, 2012

Revised: October 11, 2012

Published: October 18, 2012 
intrinsic entropy of activation $(-71.0 \mathrm{~J} /(\mathrm{mol} \mathrm{K}))$ was calculated by means of dynamical sampling techniques applied to the cracking of propane on zeolite chabazite. These results differ noticeably from recent experimental work in which intrinsic activation entropies were estimated from measured apparent kinetic parameters by assuming a temperature independent entropy of adsorption, leading to intrinsic activation entropies that are more positive than the calculated ones by $60-80 \mathrm{~J} /(\mathrm{mol} \mathrm{K}) .^{31-35}$ The objective of the present study is to contribute to a molecular level understanding of the monomolecular ${ }^{36}$ cracking of short chain alkanes on zeolite $\mathrm{H}$ ZSM-5. Intrinsic kinetic parameters are obtained directly by means of DFT calculations in combination with transition state theory and indirectly from experimental rate data using enthalpies and entropies of adsorption at reaction temperature determined from Monte Carlo (MC) simulations (see Figure 1 for the definition of apparent and intrinsic barriers in the context of alkane cracking).

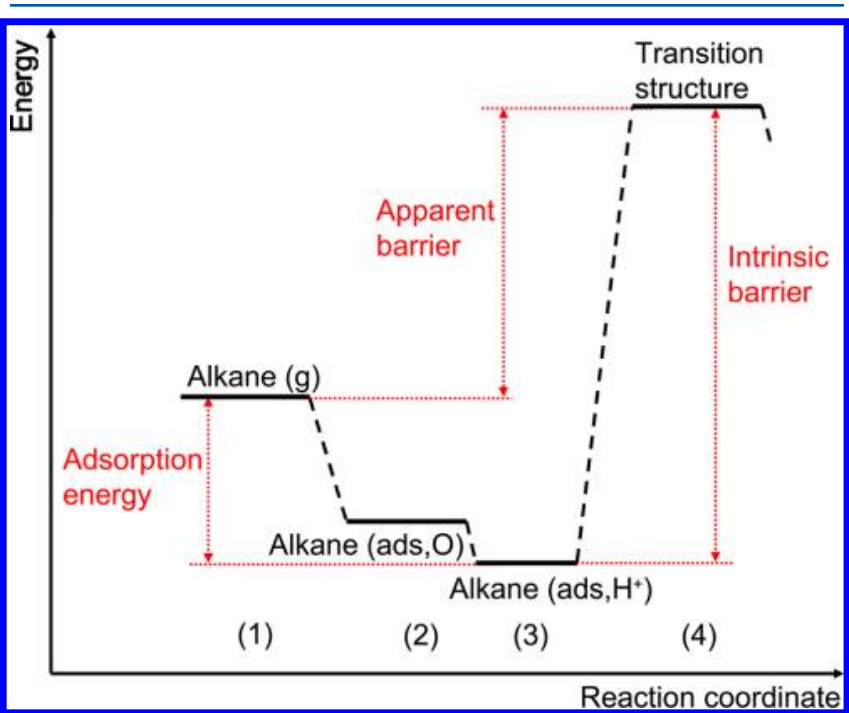

Figure 1. Energy diagram for the formation of the first transition state in zeolite-catalyzed monomolecular cracking of alkanes: (1) Reactant in the gas phase. (2) Adsorption of the alkane in the zeolite channels. (3) Adsorption on the Brønsted site. (4) Formation of the transition state. The quantity measured experimentally is the apparent barrier, to which the appropriate energy of adsorption has to be added to get the intrinsic barrier (see also ref 45 ).

On the basis of the present results, we propose an alternative partitioning of the measured entropy of activation into contributions from adsorption and intrinsic reaction.

\section{COMPUTATIONAL DETAILS}

A. DFT Calculations Applying Periodic Boundary Conditions. The DFT calculations were carried out using the program VASP (Vienna Ab Initio Simulation Package), ${ }^{37-40}$ where the electronic wave functions have been expanded into plane waves up to an energy cutoff of $400 \mathrm{eV}$, and a projected-augumented-wave $(\mathrm{PAW})^{41}$ scheme has been used to describe the interactions between the valence electrons and the nuclei (ions). To avoid interactions between periodic images of molecules, a relatively large cubic box $(25 \times 25 \times 25$ $\AA^{3}$ ) has been used for the simulations of the molecules in vacuum. As a consequence of the supercell size, only one single K-point, the Gamma point, was necessary to span the Brillouin zone. The minimum energy configurations for the molecules in vacuum were considered to be converged when the forces on each atom of the molecules were less than $0.0001 \mathrm{eV} / \AA$.

The structural model of ZSM-5 consists of an orthorhombic $^{42-44}$ unit cell with fixed edge lengths of $a=20.157 \AA$, $b=$ $20.033 \AA$, and $c=13.473 \AA$, which result from optimization of an all-silica unit cell. ${ }^{45}$ To create an acidic site, one of the $96 \mathrm{Si}$ atoms in the unit cell was replaced by an $\mathrm{Al}$ atom at the $\mathrm{T} 12$ site $^{46}$ and the resulting negative charge was compensated by a proton bonded to one of the neighboring framework oxygens. The siting of $\mathrm{Al}$ in the ZSM-5 framework is neither random nor controlled by the stabilization energy of the $\mathrm{Al}$ atoms in the framework but depends mainly on the conditions of the zeolite synthesis. ${ }^{47-49}$ Therefore, the choice of the T-site in the computational model is subject to some ambiguity. A large body of computational studies investigating reactions in ZSM-5 choose the T12 site because it is the most spacious T-site and due to some weak evidence that this site is preferred. ${ }^{50,51}$ In the present work we follow this approach, also to be consistent with our earlier study on alkane cracking on H-ZSM-5. ${ }^{9}$

Minima on the PBE potential energy surface were located using the conjugate gradient algorithm with fully relaxed atomic positions. Convergence was considered to be achieved when forces were below $10^{-4} \mathrm{eV} / \AA ̊$. Energies were converged to $10^{-5}$ $\mathrm{eV}$ in all the cases. Transition states were localized using the improved dimer method. ${ }^{52}$ Convergence was considered to be achieved when forces were below $0.05 \mathrm{eV} / \AA \AA$. Stationary points found were characterized by harmonic frequencies obtained by diagonalization of the full dynamical matrices. The force constants were obtained by numerical differentiation of forces with a step size of $0.02 \AA$. No scaling factor was applied for the frequencies.

Single-point energy calculations employing the revised form of the PBE functional proposed by Hammer et al. ${ }^{53}$ (RPBE) were conducted for each reactant and transition state to improve the estimate of intrinsic energy barriers relative to the PBE results.

Adsorption energies at $T=0 \mathrm{~K}$ were calculated from the $\mathrm{PBE}$ energies as

$$
\Delta E_{\mathrm{ads}}=E_{\text {complex }}-\left(E_{\text {alkane }}+E_{\mathrm{ZSM}-5}\right)
$$

where $E_{\text {complex }}$ is the total (electronic) energy of the adsorption complex, $E_{\text {alkane }}$ is the total energy of the alkane with optimized structure in vacuum, and $E_{\mathrm{ZSM}-5}$ is the total energy of the unloaded zeolite. Zero point corrected vibrational adsorption energies were obtained from

$$
\begin{aligned}
\Delta E_{\mathrm{ads}, 0}= & \Delta E_{\mathrm{ads}}+\sum_{\mathrm{ip}}^{\text {modes }} \frac{1}{2} h \omega_{\mathrm{ip}}-\sum_{\mathrm{is}}^{\text {modes }} \frac{1}{2} h \omega_{\mathrm{is}} \\
& -\sum_{\mathrm{iA}}^{\text {modes }} \frac{1}{2} h \omega_{\mathrm{iA}}
\end{aligned}
$$

where $\sum_{\mathrm{ip}}^{\text {modes } 1 / 2}\left(h \omega_{\mathrm{ip}}\right)$ are the vibrational frequencies corresponding to the adsorbed system, $\sum_{\mathrm{is}}^{\text {modes } 1} /{ }_{2}\left(h \omega_{\mathrm{is}}\right)$ are the vibrational frequencies corresponding to the ZSM-5 surface and $\sum_{\mathrm{iA}}^{\text {modes } 1 /{ }_{2}}\left(h \omega_{\mathrm{iA}}\right)$ are the vibrational frequencies corresponding to the gas phase molecule.

For molecules in the gas phase, the rigid-rotator harmonic oscillator approximation $^{54}$ was used when the finite temperature correction to the adsorption enthalpy was calculated. For all adsorbate and transition state complexes, corrections for finite temperatures were calculated assuming immobile 
adsorption, that is, complete conversion of frustrated rotational and translational degrees of freedom into vibrations. As far as enthalpies are concerned, this approximation is justified because their sensitivity to variations in the harmonic frequency values is weak. $^{55,56}$ However, for the calculation of adsorption entropies this treatment usually overestimates the entropy loss during adsorption. ${ }^{55-57}$ Moreover, the latter approach uses the information of only one point on the potential energy surface. Therefore, we employed a Monte Carlo sampling approach to compute the adsorption parameters as function of temperature as outlined in section II.D.

Intrinsic rate coefficients were calculated from conventional transition state theory ${ }^{58-60}$

$$
k(T)=\frac{k_{\mathrm{B}} T}{h} \frac{Q_{\mathrm{TS}}(T)}{Q_{\mathrm{R}}(T)} \exp \left[-E^{\ddagger} / R T\right]
$$

where $k_{\mathrm{B}}$ is Boltzmann's constant, $h$ is Planck's constant, $T$ is the absolute temperature, and $E^{\ddagger}$ is the difference in electronic energies between the transition state and reactant state. With $Q_{T S}$ and $Q_{R}$, we denote the partition functions of the transition state and the reactant state, respectively evaluated using only vibrational modes.

B. Dispersion Corrections to PBE Results. van der Waals $(\mathrm{vdW})$ interactions between atoms and molecules caused by long-range electron correlation contribute significantly to the alkane heat of adsorption and may affect both the mechanism and the kinetics of alkane conversion. ${ }^{61,62}$ However, functionals which can be used efficiently in periodic solid-state simulations do not properly account for long-range dispersion interactions $^{63,64}$ and are subject to the self-interaction error. ${ }^{65-68}$ Many of the computational approaches that can be used to describe dispersion interactions such as the treatment of dynamical correlations within the random phase approximation (RPA) connected with the fluctuation dissipation theorem, ${ }^{69,70}$ the Langreth method, ${ }^{71}$ or MP2 calculations are hardly feasible for extended systems such as zeolites. A computationally less demanding approach consists of adding a pairwise interatomic $C_{6} R^{-6}$ term to the DFT energy. ${ }^{72-79}$ Here we adopted the semiempirical approach of Grimme. ${ }^{72-74}$ The total energy can be written as

$$
E_{\mathrm{TOTAL}}=E_{\mathrm{PBE}}+E_{\mathrm{DISP}}
$$

where $E_{\mathrm{PBE}}$ is the electronic energy and $E_{\mathrm{DISP}}$ is an empirical dispersion correction term.

For periodic systems it involves the evaluation of

$$
E_{\mathrm{DISP}}=-\frac{1}{2} \sum_{L} \sum_{i, j \in L=0} \frac{C_{6}^{i j}}{\left|R_{i j}-L\right|^{6}} f_{\mathrm{d}}\left(\left|R_{i j}-L\right|\right)
$$

where $C_{6}^{i j}$ denotes the dispersion coefficients, $R_{i j}$ are the interatomic distances, $f_{d}\left(R_{i j}\right)$ represents the damping function, and $L$ is the direct lattice translation vector, while $i$ and $j$ are the atoms within the central unit cell with the condition $i \neq j$ for $L$ $=0$.

In the present work eq 5 was evaluated by means of lattice sums ${ }^{80}$ using the transferable $C_{6}$-parameters reported by Grimme. ${ }^{73}$ This approach has been applied successfully to a variety of guest molecules in a diverse set of host structures, including several studies of zeolites, ${ }^{29,45,80-82}$ leading us to conclude that this semiempirical approach can also be used successfully to estimate adsorption energies of alkanes in zeolites.
C. Transition Path Sampling. There are several methods available for obtaining reaction pathways. The traditional approach has been to find transition states, or local saddle points, and then follow the imaginary mode to find the reactants and the products associated with the transition state. ${ }^{83}$ A more comprehensive approach would involve sampling various dynamic pathways that are representative of the true reaction process, ${ }^{83}$ such as realized in transition path sampling (TPS). ${ }^{84-91}$ Other path finding algorithms, including the recently developed transition-path theory (TPT) are discussed by $\mathrm{E}$ and Vanden-Eijnden. ${ }^{92}$

In the TPS method, the reactive trajectory is an equilibrium object defined as an ordered sequence of states (i.e., atomic positions and corresponding momenta) connecting reactant and product. Here we have used the TPS implementation described in refs 61 and 62. The initial trajectory has been obtained by forward and backward integration of the equations of motion starting from a configuration close to the transition state and randomly generated momenta. The simulations were performed in the canonical ensemble.

D. Monte Carlo Simulations. The enthalpy and entropy of adsorption were estimated for rigid all-silica and acidic representations of ZSM-5 using the Widom test insertion method. ${ }^{93}$ The interactions of a single adsorbate molecule with the all-silica zeolite framework were modeled with a LennardJones-type potential using the force-field parameters of Dubbeldam et al. ${ }^{94,95}$ To model the effect of the presence of Brønsted-acid sites in the zeolite framework, we performed a set of simulations with certain framework oxygen atoms given interaction parameters meant to approximate the stronger interaction of alkanes with the acid site compared to the rest of the framework. One of the $12 \mathrm{~T}$-sites was selected and the four oxygens bonded to it were replaced with pseudoatoms possessing larger well-depth $(\varepsilon)$ parameters in the LennardJones potential. The distance $(\sigma)$ parameters for all interactions remained the same. The numerical values of these $\varepsilon$-parameters for the $\mathrm{CH}_{2}-\mathrm{O}$ and $\mathrm{CH}_{3}-\mathrm{O}$ interactions were taken from ref 9 (see Supporting Information, Table S.3 therein). In the latter work the parameters were adjusted to reproduce the observed enhancement of the heat of adsorption of $n$-hexane in H-ZSM5 at lower temperatures of about $-10 \mathrm{~kJ} / \mathrm{mol}$ relative to the pure-silica form of the structure. ${ }^{96,97}$ Simulations were performed for each of the $12 \mathrm{~T}$-site symmetries providing the influence of the particular T-site location on the adsorption enthalpy and entropy.

For each temperature two simulations were performed, one in an ideal gas phase and one in the adsorbed state. Ensemble averages were computed from 50 million insertions at each temperature. The original Widom test particle method relates the free energy to the energy of a test particle. For chain molecules it is more convenient to use a similar expression in terms of Rosenbluth factors 99,100

$$
\Delta A=-R T \log \frac{\langle W\rangle}{\left\langle W_{\mathrm{ig}}\right\rangle}
$$

where $\Delta A$ is the change in Helmholtz free energy and $\langle W\rangle$ and $\left\langle W_{\text {ig }}\right\rangle$ are the Rosenbluth factors of the adsorbate in the zeolite and in an ideal gas phase (no interactions with the zeolite). With $R$ and $T$ we denote the gas constant and the absolute temperature, respectively. The entropy of adsorption was obtained from 


$$
\Delta S_{\mathrm{ads}}=\frac{(\Delta U-\Delta A)}{T}=\frac{\left\langle U_{\mathrm{hg}}\right\rangle-\left\langle U_{\mathrm{g}}\right\rangle}{T}+R \log \frac{\langle W\rangle}{\left\langle W_{\mathrm{ig}}\right\rangle}
$$

where $\Delta U$ denotes the difference in the average host-guest $\left(\left\langle U_{\mathrm{hg}}\right\rangle\right)$ and gas phase energies $\left(\left\langle U_{\mathrm{g}}\right\rangle\right)$. The enthalpy was obtained from

$$
\Delta H_{\mathrm{ads}}=\left\langle U_{\mathrm{hg}}\right\rangle-\left\langle U_{\mathrm{g}}\right\rangle-R T
$$

\section{RESULTS AND DISCUSSION}

A. PBE Adsorption Energies. Table 1 summarizes the $\mathrm{PBE}$ and dispersion contributions to the adsorption energies of

Table 1. DFT (PBE) and Dispersion Contributions (in kJ/ mol) to Reactant Adsorption Energies ${ }^{a}$

$\begin{array}{cccc}\text { molecule } & \Delta E_{\text {ads }}(\mathrm{PBE}) & \Delta E_{\text {ads }}(\mathrm{vdW}) & \Delta E_{\text {ads }}(\mathrm{PBE}+\mathrm{D}) \\ \mathrm{C}_{3} \mathrm{H}_{8} & -8.7 & -39.5 & -48.2(-47.9) \\ \mathrm{C}_{4} \mathrm{H}_{10} & -9.2 & -54.6 & -63.8(-62.6) \\ \mathrm{C}_{5} \mathrm{H}_{12} & -8.2 & -71.3 & -79.5(-78.3) \\ \mathrm{C}_{6} \mathrm{H}_{14} & -5.3 & -87.3 & -92.6(-91.0)\end{array}$

${ }^{a}$ Zero-point energy corrected values are reported in parentheses.

all reactants on the acid site. The absence of imaginary frequencies confirmed that all stationary points were true minima. Although the PBE interaction energy does not show a distinct chain length dependence, the dispersion contribution strongly increases, as expected. Table 2 compares adsorption

Table 2. Dispersion Corrected Adsorption Enthalpies for Reactant Molecules

$\begin{array}{cccc}\text { molecule } & T[\mathrm{~K}] & \Delta H_{\text {ads }}(\mathrm{DFT}+\mathrm{D})[\mathrm{kJ} / \mathrm{mol}] & \Delta H_{\text {ads }}(\operatorname{exptl})^{a}[\mathrm{~kJ} / \mathrm{mol}] \\ \mathrm{C}_{3} \mathrm{H}_{8} & 573 & -40.1 & -40^{(1)}(\infty),-43^{(2)}(35) \\ & 773 & -36.8 & \\ \mathrm{C}_{4} \mathrm{H}_{10} & 573 & -54.9 & -49^{(1)}(\infty),-62^{(2)}(35) \\ & 773 & -51.6 & \\ \mathrm{C}_{5} \mathrm{H}_{12} & 573 & -70.5 & -58^{(3)}(137),-74^{(2)}(35) \\ & 773 & -67.2 & \\ \mathrm{C}_{6} \mathrm{H}_{14} & 573 & -83.8 & -69^{(3)}(137),-92^{(3)}(35) \\ & 773 & -80.7 & \end{array}$

${ }^{a}$ Experimental data from (1) Sun et al., ${ }^{102}$ (2) Narbeshuber et al. ${ }^{101}$ and (3) Denayer et al. ${ }^{103} \mathrm{The} \mathrm{Si} / \mathrm{Al}$ ratio is reported in parentheses.

enthalpies, calculated from the dispersion corrected adsorption energies by adding zero-point vibrational energies and thermal corrections evaluated from PBE frequencies, with available experimental data. In the low-coverage regime, experimental adsorption enthalpies strongly depend on the $\mathrm{Si} / \mathrm{Al}$ ratio and the synthesis method of the zeolite sample, leading to a significant scatter across the literature. $^{98}$ The experimental data selected for Table 2 are representative for zeolites with high (less than one acid site per unit cell) and low (about three acid sites per unit cell) $\mathrm{Si} / \mathrm{Al}$ ratios. ${ }^{101-103}$ For propane the agreement with experiment is remarkable whereas for the longer alkanes the calculated numbers are between the experimental numbers showing an overall good agreement. Note that a more detailed quantitative comparison is difficult because the calculated value refers to one particular acid site and adsorbate configuration, chosen such that the adsorbate can maximize its interaction with the proton and the zeolite surface, whereas the experimental sample contain a distribution of sites over different crystallographic positions. Keeping in mind these uncertainties, it can be concluded that eq 5 offers a computationally efficient route to estimate the heat of adsorption of alkanes in zeolites.

B. Intrinsic Rate Parameters. Table 3 reports intrinsic energy barriers for monomolecular cracking of propane to

Table 3. DFT (RPBE) Results for Intrinsic Energy Barriers (Without Dispersion) for Monomolecular Cracking ${ }^{a}$

$\begin{array}{ccc}\text { reactant } & E^{\ddagger}[\mathrm{kJ} / \mathrm{mol}] & \text { products } \\ \mathrm{C}_{3} \mathrm{H}_{8} & 195.6(172.8) & \mathrm{CH}_{4}+\mathrm{C}_{2} \mathrm{H}_{4} \\ \mathrm{C}_{4} \mathrm{H}_{10} & 197.4(175.7) & \mathrm{CH}_{4}+\mathrm{C}_{3} \mathrm{H}_{6} \\ \mathrm{C}_{5} \mathrm{H}_{12} & 187.4(169.8) & \mathrm{C}_{3} \mathrm{H}_{8}+\mathrm{C}_{2} \mathrm{H}_{4} \\ \mathrm{C}_{6} \mathrm{H}_{14} & 189.8(167.2) & \mathrm{C}_{3} \mathrm{H}_{8}+\mathrm{C}_{3} \mathrm{H}_{6}\end{array}$

${ }^{a} \mathrm{PBE}$ results are reported in parentheses.

methane and ethene, $n$-butane to methane and propene, $n$ pentane to propane and ethene, and $n$-hexane to propane and propene. The frequency analysis revealed the presence of exactly one imaginary frequency for all transition states. Visualization of the normal modes corresponding to the imaginary frequencies was used to confirm that they indeed corresponded to the expected motion of atoms. The transition state structures are displayed in Figure 2. The PBE energy barriers are about $20 \mathrm{~kJ} / \mathrm{mol}$ lower than the ones obtained using the RPBE functional, the latter allowing for a more

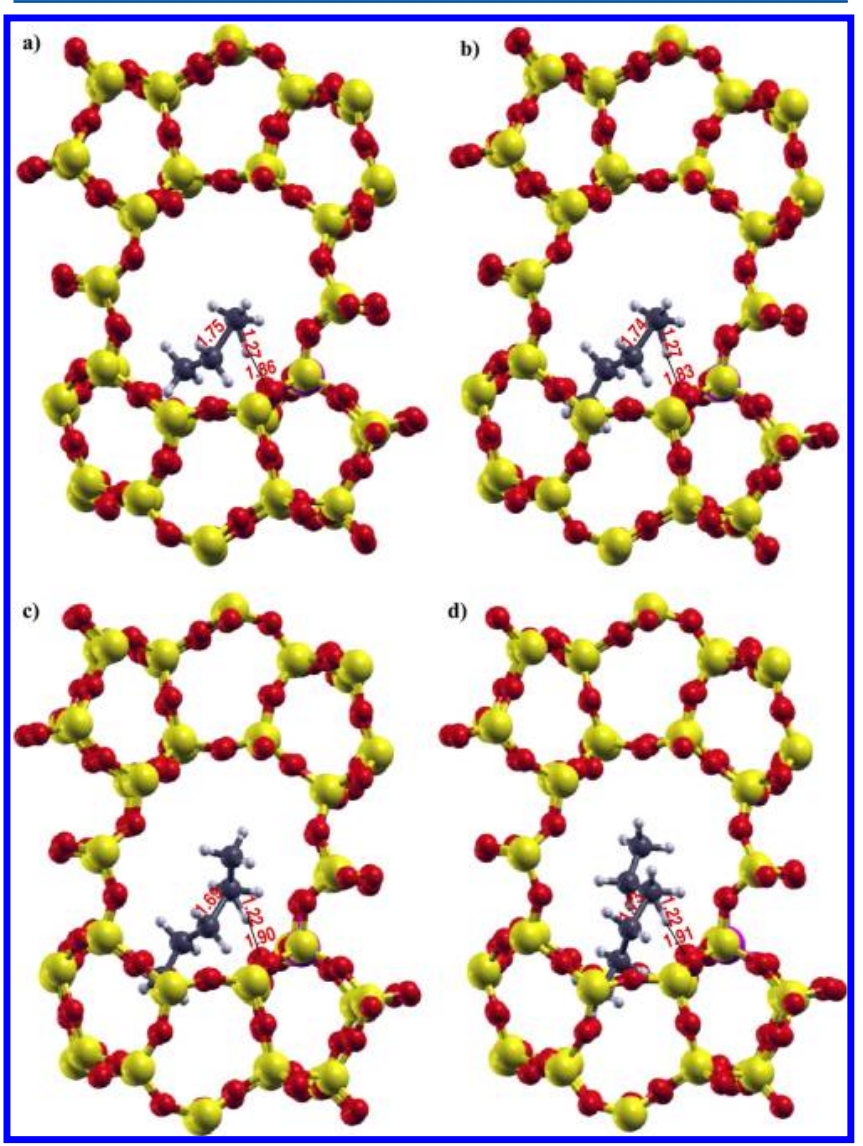

Figure 2. Transition state for cracking of (a) $\mathrm{C}_{3} \mathrm{H}_{8}$, (b) $\mathrm{C}_{4} \mathrm{H}_{10}$, (c) $\mathrm{C}_{5} \mathrm{H}_{12}$, and (d) $\mathrm{C}_{6} \mathrm{H}_{14}$. Interatomic distances are given in $\AA$. Colors: carbon, dark gray; hydrogen, white; oxygen, light red; silicon, light orangel; aluminum, purple. 
Table 4. Intrinsic Activation Enthalpy, Entropy, Gibbs Free Energy, and Rate Constant for Monomolecular $\mathrm{Cracking}$ of $\mathrm{C}_{3} \mathrm{H}_{8}$, $\mathrm{C}_{4} \mathrm{H}_{10}, \mathrm{C}_{5} \mathrm{H}_{12}$, and $\mathrm{C}_{6} \mathrm{H}_{14}$ a

\begin{tabular}{|c|c|c|c|c|c|c|}
\hline reactant & $T[\mathrm{~K}]$ & $\Delta H_{\mathrm{int}}^{\ddagger}(\mathrm{DFT})[\mathrm{kJ} / \mathrm{mol}]$ & $\Delta S_{\text {int }}^{\ddagger}(\mathrm{DFT})[\mathrm{J} /(\mathrm{mol} \mathrm{K})]$ & $\Delta G_{\text {int }}^{\ddagger}(\mathrm{DFT})[\mathrm{kJ} / \mathrm{mol}]$ & $k_{\text {int }}(\mathrm{DFT})[1 / \mathrm{s}]$ & $\Delta H_{\text {int }}^{\ddagger}(\operatorname{exptl})^{b}[\mathrm{~kJ} / \mathrm{mol}]$ \\
\hline \multirow[t]{2}{*}{$\mathrm{C}_{3} \mathrm{H}_{8}$} & 573 & 179.7 & -67.0 & 218.1 & $0.15 \times 10^{-6}$ & \\
\hline & 773 & 179.0 & -68.1 & 231.6 & $0.35 \times 10^{-2}$ & $187^{(1)}, 192^{(2)}$ \\
\hline \multirow[t]{2}{*}{$\mathrm{C}_{4} \mathrm{H}_{10}$} & 573 & 180.9 & -64.2 & 217.7 & $0.17 \times 10^{-6}$ & \\
\hline & 773 & 180.1 & -65.4 & 230.7 & $0.42 \times 10^{-2}$ & $191^{(2)}$ \\
\hline \multirow[t]{2}{*}{$\mathrm{C}_{5} \mathrm{H}_{12}$} & 573 & 171.3 & -34.3 & 190.8 & $0.48 \times 10^{-4}$ & \\
\hline & 773 & 170.6 & -35.2 & 197.7 & $0.70 \times 10^{0}$ & $188^{(2)}$ \\
\hline \multirow[t]{2}{*}{$\mathrm{C}_{6} \mathrm{H}_{14}$} & 573 & 175.8 & -19.0 & 186.7 & $0.12 \times 10^{-3}$ & \\
\hline & 773 & 175.1 & -20.1 & 190.6 & $0.21 \times 10^{+1}$ & $191^{(2)}$ \\
\hline
\end{tabular}

${ }^{a}$ Dispersion contributions are not included in the reported energies. ${ }^{b}$ The intrinsic enthalpies of activation were obtained from reported intrinsic energies of activation, $E_{\mathrm{a}}$, using the relation ${ }^{104} \Delta H_{\mathrm{int}}^{\ddagger}=E_{\mathrm{a}}-R T$ with $R T \approx 6 \mathrm{~kJ} / \mathrm{mol}$ at $773 \mathrm{~K}$. The experimental values for $E_{\mathrm{a}}$ were taken from $(1)$ $\mathrm{Xu}$ et al. ${ }^{105}$ and (2) Narbeshuber et al. ${ }^{101}$.

realistic estimation of barriers heights, as is shown in Table 4. This table summarizes intrinsic enthalpy barriers obtained from the RPBE energy barriers after applying zero-point vibrational energy and thermal corrections, intrinsic activation entropies, Gibbs energies, and rate coefficients. The comparison to experimental data ${ }^{101,105}$ requires an assumption about the appropriate enthalpy of adsorption used to convert measured (apparent) energy barriers to intrinsic ones. The results reported by Narbeshuber et al. ${ }^{101}$ suggest a virtually constant intrinsic energy barrier consistent with the results of the present study, bearing in mind that variations of about $10 \mathrm{~kJ} / \mathrm{mol}$ between the calculated energy barriers are within the uncertainties of these numbers. Assuming a different set of adsorption enthalpies, intrinsic energy barriers would be obtained that show a decrease of about $5 \mathrm{~kJ} / \mathrm{mol}$ per $\mathrm{CH}_{2}$ unit. However, in the case of propane this ambiguity has the smallest effect such that we restrict a more detailed comparison to this molecule. Here, the use of the RPBE functional to estimate barrier heights provides a significant improvement compared to the PBE results, with a remaining underestimation of about $10 \mathrm{~kJ} / \mathrm{mol}$. We attribute this discrepancy to the known shortcomings of GGA functionals to estimate barriers heights ${ }^{106,109}$ and to uncertainties introduced by the restriction to one particular acid site. The first point could in principle be remedied by the use of sophisticated correction schemes, such as the MP2:DFT hybrid method presented by Tuma and Sauer. ${ }^{108}$ Applying the latter approach to a variety of hydrocarbon reactions in zeolites ${ }^{45,82,109}$ has demonstrated that barrier heights can be estimated with high accuracy following an elaborated computational protocol. The second point was addressed recently by Zimmerman et al. ${ }^{110}$ who showed that the sensitivity of the cracking barrier to the acid site position ( $\mathrm{T} 12$ vs $\mathrm{T} 3$ ) can be as large as $13-25 \mathrm{~kJ} / \mathrm{mol}$ for the cracking of propane and hexane on zeolite H-ZSM-5, respectively. We therefore conclude that the reasons for the residual discrepancy between calculated and experimental energy barriers are well understood but the elimination of them requires a significant computational burden, beyond the scope of the present work.

Regarding intrinsic entropies of activation for alkane cracking in ZSM-5 there is less consensus in the computational and experimental literature. Computational difficulties arise from the fact that harmonic transition state theory (TST) is often not a correct model due to strongly anharmonic hindered rotations and translations of the adsorbed molecules and a usually strong coupling of reactive and vibrational motion in the barrier region, ${ }^{111}$ making more demanding dynamical sampling techniques necessary. However, such calculations are subject to serious convergence issues for systems as large as the ones studied in the present work. For propane cracking in chabazite though, an intrinsic activation entropy obtained from thermodynamic integration over free-energy gradients, evaluated by constrained $\mathrm{ab}$ initio $\mathrm{MD}$ simulations along a path connecting initial and transition state, was reported by Bučko et al. ${ }^{30}$ The remarkable agreement between the value from the latter work, $\Delta S_{\text {int }}^{\ddagger}=-71.0 \mathrm{~J} /(\mathrm{mol} / \mathrm{K})$, and the value obtained in the present work on the basis of harmonic TST, $\Delta S_{\text {int }}^{\dagger}=-68.1$ $\mathrm{J} /(\mathrm{mol} \mathrm{K})$, points toward the applicability of harmonic TST for this particular case. To further validate (or invalidate) the intrinsic entropies of activation obtained in the present work, we made use of the results from Monte Carlo simulations as outlined in the next section.

C. Monte Carlo Analysis. The theoretical results for the intrinsic activation entropy for the monomolecular cracking of propane reported in ref 30 and in the present work are in apparent disagreement with recent experimental work, ${ }^{31-35}$ reporting intrinsic entropies of activation in the range of -8.6 to $+16 \mathrm{~J} /(\mathrm{mol} \mathrm{K})$. The latter estimates are based on measured (apparent) entropies of activation and literature data for the entropy of adsorption of propane at $350 \mathrm{~K}, \Delta S_{\mathrm{ads}}=-103 \mathrm{~J} /$ $(\mathrm{mol} \mathrm{K}),{ }^{97}$ using the relation $\Delta S_{\text {int }}^{\ddagger}=\Delta S_{\text {meas }}^{\ddagger}-\Delta S_{\text {ads }}$.

However, the underlying assumption of a temperature independent entropy of adsorption is questionable considering the qualitative difference in the adsorption process at low and high temperatures. At present there are no experimental data to support this assumption, but molecular simulations on all-silica MFI have shown that there is a significant temperature dependence. ${ }^{112}$ For the acid form of MFI, at lower temperatures, the presence of these acid sites lead to an additional stabilization of the adsorbed molecule of the order of $10 \mathrm{~kJ} /$ $\mathrm{mol}^{97}$ that will also cause a more negative entropy of adsorption compared to purely siliceous zeolites. At higher temperatures the molecule becomes more and more detached from the acid site, which will lead to a first decrease in the magnitude of the entropy loss due to adsorption, by approximately the difference between H-ZSM-5 and silicalite. The significant scatter in experimental entropies of adsorption for propane in silicalite does not allow for an exact quantification of this difference but the reported values, ranging from -80 to $-44 \mathrm{~J} /(\mathrm{mol}$ $\mathrm{K}){ }^{113-115}$ are substantially different from $-103 \mathrm{~J} /(\mathrm{mol} \mathrm{K})$. An additional decrease in the magnitude of the entropy of adsorption will be caused by an increased mobility of the adsorbate. 


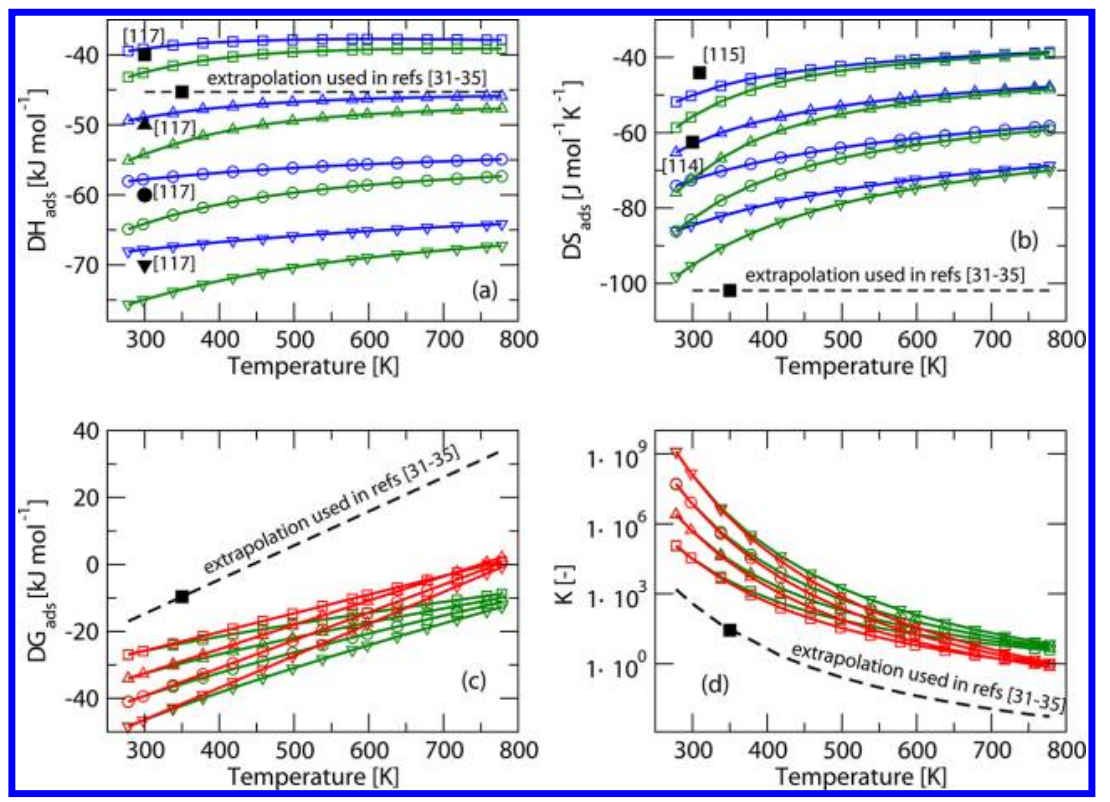

Figure 3. Parameters related to the adsorption of propane (squares), $n$-butane (triangles up), $n$-pentane (circles), and $n$-hexane (triangles down) in silicalite and H-ZSM-5. (a) Heat of adsorption as function of temperature. The open symbols represent the MC simulation results for silicalite (blue) and H-ZSM-5 (green); the filled symbols represent experimental data (references are given in brackets). (b) Entropy of adsorption as function of temperature. The open symbols represent the MC simulation results for silicalite (blue) and H-ZSM-5 (green); the filled symbols represent experimental data (references are given in brackets). (c) Free energy of adsorption as function of temperature. The open symbols represent the results obtained from simulated enthalpies and entropies for H-ZSM-5 according to $\Delta G_{\text {ads }}(T)=\Delta H_{\text {ads }}(T)-T \Delta S_{\text {ads }}(T)$ (green) and $\Delta G_{\text {ads }}(T)=$ $\Delta H_{\text {ads }}(298)-T \Delta S_{\text {ads }}(298)$ (red). The filled symbols represent the free energy of adsorption for propane based on constant experimental values for $\Delta H_{\text {ads }}$ and $\Delta S_{\text {ads }}$ as used in refs 31-35 to analyze measured kinetic data. (d) Adsorption equilibrium constant $K=\exp \left(-\Delta G_{\text {ads }} /(R T)\right)$ as a function of temperature. The open symbols represent the results obtained using $\Delta G_{\text {ads }}(T)=\Delta H_{\text {ads }}(T)-T \Delta S_{\text {ads }}(T)($ green $)$ and $\Delta G_{\text {ads }}(T)=\Delta H_{\text {ads }}(298)-$ $T \Delta S_{\text {ads }}(298)$ (red). The filled symbols represent the adsorption equilibrium constant for propane based on constant experimental values for $\Delta H_{\text {ads }}$ and $\Delta S_{\text {ads }}$ as used in refs $31-35$ to analyze measured kinetic data.

Table 5. Extraction of Intrinsic Entropies of Activation for the Monomolecular Cracking of $\mathrm{C}_{3}$ to $\mathrm{C}_{6}$ alkanes at $773 \mathrm{~K}^{a}$

\begin{tabular}{|c|c|c|c|c|c|c|c|}
\hline \multirow[b]{3}{*}{ carbon no. } & \multirow[b]{3}{*}{$\mathrm{TOF}^{b}$} & \multicolumn{3}{|c|}{$K[-]^{c}$} & \multicolumn{3}{|c|}{$\Delta S_{\text {int }}^{\ddagger}[\mathrm{J} /(\mathrm{mol} \mathrm{K})]$} \\
\hline & & \multicolumn{2}{|c|}{ this work (MC) } & \multirow{2}{*}{$\frac{\text { ref } 31}{T \text {-indep }}$} & \multicolumn{2}{|c|}{ this work (MC) } & \multirow{2}{*}{$\begin{array}{c}\text { ref } 31 \\
T \text {-indep }\end{array}$} \\
\hline & & T-dep & $T$-indep $^{d}$ & & $T$-dep & $T$-indep & \\
\hline 3 & $1.31 \times 10^{-3}$ & 4.02 & 0.90 & 0.0055 & -63.4 & -51.1 & -8.6 \\
\hline 4 & $5.80 \times 10^{-3}$ & 4.87 & 0.77 & 0.0051 & -54.0 & -38.6 & +3.0 \\
\hline 5 & $2.23 \times 10^{-2}$ & 6.00 & 0.99 & 0.0046 & -48.4 & -33.4 & +11.0 \\
\hline 6 & $6.00 \times 10^{-2}$ & 7.61 & 1.22 & 0.0046 & -38.3 & -23.0 & +23.0 \\
\hline
\end{tabular}

${ }^{a}$ The analysis is based on eq 9 using the intrinsic activation energies reported by Narbeshuber ${ }^{101}$ and adsorption equilibrium constants obtained from temperature dependent ( $T$-dep.) or temperature independent ( $T$-indep) enthalpies and entropies of adsorption. ${ }^{b}$ Turnover frequencies in $[\mathrm{mol}$ $\left.\left(\mathrm{mol} \mathrm{H}^{+}\right)^{-1} \mathrm{~s}^{-1} \mathrm{bar}^{-1}\right]$ taken from ref 31. ${ }^{c}$ Note that this analysis relies on the numerical identity of the dimensionless thermodynamic adsorption equilibrium constant $K=\exp (-\Delta G / R T)$ and the Langmuir equilibrium constant $K_{\mathrm{L}}=K / P^{\circ}$ with the unit of [bar ${ }^{-1}$ ] and a standard state pressure of $P^{\circ}=1$ bar, as discussed for example in refs 56,122 , and 123 . ${ }^{d}$ Adsorption enthalpy and entropy fixed to simulated values obtained at $298 \mathrm{~K}$. ${ }^{e}$ Adsorption enthalpy and entropy fixed to experimental values obtained at $350 \mathrm{~K} \cdot{ }^{96,97}$

The temperature dependence of the enthalpy, entropy and free energy of adsorption as well as of the adsorption equilibrium constant obtained from Monte Carlo simulations are displayed in Figure 3. The results show that both enthalpy and entropy become less negative with increasing temperature. The temperature dependence of $\Delta H_{\text {ads }}$ and $\Delta S_{\text {ads }}$ becomes stronger for longer chains, in agreement with earlier Monte Carlo simulations for longer alkanes. ${ }^{116}$ The presence of Brønsted sites in the Monte Carlo model has a substantial effect on the calculated enthalpy and entropy of adsorption at lower temperature. At $298 \mathrm{~K}$ the enthalpies are more negative by $3.4-7.2 \mathrm{~kJ} / \mathrm{mol}$ when proceeding from propane to hexane whereas the entropies are more negative by $5.7-10.7 \mathrm{~J} /(\mathrm{mol}$ K) (values for Brønsted sites averaged over all positions). These differences decrease with increasing temperature, showing that the interactions between the acid site and the alkane are relatively nonspecific and insufficient to keep the alkane localized at the acid sites. The calculated enthalpies of adsorption at $298 \mathrm{~K}$ are in good agreement with experimental data. ${ }^{101,117}$ Experimental data for adsorption entropies are more diverse than those for adsorption enthalpies. ${ }^{97,113-115,118-121}$ Therefore, we restrict the comparison to propane. Our calculated values for propane are in reasonable agreement with those reported in refs 114 and 115, but they differ significantly from those reported in ref 97 . However, the latter value of $\Delta S_{\text {ads }}=-103 \mathrm{~J} /(\mathrm{mol} \mathrm{K})$ together with an adsorption enthalpy of $\Delta H_{\mathrm{ads}}=-45 \mathrm{~kJ} / \mathrm{mol}$ was used in recent experimental studies to extract intrinsic rate parameters from measured reaction rates, ${ }^{31-35}$ assuming that these adsorption parameters are temperature independent (illustrated by the 
dotted line in Figure 3). The consequences of this assumption are displayed in panels $\mathrm{c}$ and $\mathrm{d}$ of Figure 3. Assuming temperature independent adsorption parameters, the slope of the free energy of adsorption as function of temperature is larger (red curves in Figure 3c) than in the case of temperature dependent parameters (green curves in Figure 3c). As a result, the adsorption equilibrium constants (shown in panel $d$ ) assuming temperature independent parameters are smaller than the ones obtained from temperature dependent parameters. Also shown in panels $\mathrm{c}$ and $\mathrm{d}$ are the free energy of adsorption and equilibrium constant obtained using constant adsorption parameters of $\Delta S_{\mathrm{ads}}=-103 \mathrm{~J} /(\mathrm{mol} \mathrm{K})$ and $\Delta H_{\mathrm{ads}}=-45 \mathrm{~kJ} /$ mol for propane. $31-35$

The adsorption equilibrium constants calculated in the present work allow for a reinterpretation of measured rate data in terms of the underlying intrinsic rate parameters for monomolecular cracking of propane $e^{31-35}$ to hexane. ${ }^{31,34}$ This reanalysis is presented in Table 5 on the basis of the apparent rate coefficients and intrinsic energy barriers used in ref 31 . The underlying equation used in ref 31 to extract intrinsic activation entropies from apparent rate coefficients, $k_{\text {app }}$, reads

$$
\frac{\Delta S_{\text {int }}^{\ddagger}}{R}=\ln \left[\frac{k_{\text {app }}}{K \exp \left(-E^{\ddagger} / R T\right)} \cdot\left(\frac{k_{\mathrm{B}} T}{h}\right)^{-1}\right]
$$

where $K$ denotes the adsorption equilibrium constant, $E^{+}$is the intrinsic energy barrier, $k_{\mathrm{B}}$ is the Boltzmann constant, and $h$ is the Planck constant. Note that an implicit assumption hidden in this analysis is that once an alkane is adsorbed it immediately forms an adsorption complex with the Brønsted site, i.e., is in the reaction state. We showed in previous work that this assumption is a strong simplification because the probability of being in the reaction state decreases with increasing temperature. ${ }^{9}$ Bučko et al. showed that at $800 \mathrm{~K}$ the calculated likelihood to form an adsorption complex for propane in chabazite has decreased to $18 \%$ compared to $68 \%$ at $300 \mathrm{~K}$ (see Figure 4 in ref 30 and Figures 5 and 6 in ref 124). However, the present analysis focuses on the influence of the selected adsorption parameters on the extracted intrinsic entropy of activation and therefore neglects the lower probability, also to be comparable with ref 31 .

The adsorption equilibrium constants calculated in this work from temperature dependent adsorption parameters are larger than those used in ref 31 by a factor of 730-1655 when proceeding from propane to hexane. As a result, the intrinsic entropies of activation are more negative by $55-61 \mathrm{~J} /(\mathrm{mol} \mathrm{K})$. When performing the same analysis with temperature independent parameters (fixed to the values calculated at 298 $\mathrm{K})$, we obtain smaller adsorption equilibrium constants, leading to intrinsic entropies of activation that are less negative by $12-$ $15 \mathrm{~J} /(\mathrm{mol} \mathrm{K})$ compared to the values obtained using temperature dependent parameters. From this analysis it becomes evident that the selection of an appropriate value of $\Delta S_{\text {ads }}$ is most important followed by the consideration of the temperature dependence.

To the best of our knowledge there are no experimental data that can confirm whether our MC predictions of the entropies of adsorption (or, equivalently, whether the assumption used in refs 31-35) are correct. One argument in favor of the present results is the remarkable agreement between the intrinsic entropy of activation for propane calculated by means of transition state theory and the one calculated independently from the analysis based on eq 9. Also for the longer alkanes the agreement between the two methods is good and both approaches predict an increase of the intrinsic entropy of activation with increasing carbon number.

We therefore suggest an alternative partitioning of the apparent entropy of activation for monomolecular cracking of short alkanes in favor of a significantly more negative contribution from the intrinsic reaction than usually assumed. $^{31-35}$ Note that the sum of $\Delta S_{\text {ads }} \approx-40 \mathrm{~J} /(\mathrm{mol} / \mathrm{K})$ and $\Delta S_{\text {int }}^{\ddagger} \approx-65 \pm 3 \mathrm{~J} /(\mathrm{mol} \mathrm{K})$ obtained in this work is in good agreement with the reported ${ }^{33}$ apparent entropy of activation of $\Delta S_{\text {meas }}^{\ddagger}=-99 \pm 8 \mathrm{~J} /(\mathrm{mol} \mathrm{K})$ for the cracking of propane.

D. Transition Path Sampling. In the present work we have used the TPS approach to study qualitatively the cracking of $n$-butane on ZSM-5. Figure 4 shows a series of snapshots highlighting structural changes along the reaction path. The TPS calculations have been performed at a temperature of $T=$ $800 \mathrm{~K}$.

- Figure 4a shows the butane molecule adsorbed on the ZSM-5 surface. The distance between the acidic proton and the zeolite is $d(\mathrm{O} \cdots \mathrm{H})=0.95 \AA$, whereas the distance between the acidic proton and the closest carbon atom is $d(\mathrm{H} \cdots \mathrm{C})=2.02 \AA$.

- Figure $4 \mathrm{~b}$ shows the $\alpha$-bond approaching the acidic proton. In this snapshot, the $\mathrm{O}-\mathrm{H}$ distance is $d(\mathrm{O} \cdots \mathrm{H})$ $=1.20 \AA$ and the $\mathrm{C}-\mathrm{H}$ distance is $d(\mathrm{C} \cdots \mathrm{H})=1.78 \AA$.

- Figure $4 \mathrm{c}$ illustrates the moment at which the proton is almost transferred from the zeolite acid site to the $\alpha$ bond. The interatomic distances are $d(\mathrm{O} \cdots \mathrm{H})=1.38 \AA$ and $d(\mathrm{H} \cdots \mathrm{C})=1.62 \AA$.

- Figure $4 \mathrm{~d}$ shows the penta-coordinated alkanium ion ${ }^{125}$ forming the transition state. The interatomic distances are $d(\mathrm{O} \cdots \mathrm{H})=1.85 \AA$ and $d(\mathrm{H} \cdots \mathrm{C})=1.31 \AA$.

- Figure 4e illustrates how the alkanium ion decomposes toward the product state.

- Figure $4 \mathrm{f}$ shows the two cracking products $\left(\mathrm{CH}_{4}+\right.$ $\mathrm{C}_{3} \mathrm{H}_{6}$ ) present in the intersection region after a proton has been transferred back to the zeolite lattice.

These results indicate that the reaction mechanism studied at $0 \mathrm{~K}$, i.e., the interaction of the acidic proton with the $\mathrm{C}-\mathrm{C}$ bond to be broken, leading to the formation of bonds with both a methyl group and a methylene group, also occurs at reaction temperature. However, TPS simulations performed by Bučko et $\mathrm{al}^{30}$ show that the alternative mechanism, i.e., the interaction of the acidic proton with a terminal methyl group followed by a shift of a different hydrogen atom from the terminal carbon toward the $\mathrm{C}-\mathrm{C}$ bond to be broken, takes place simultaneously and is even the dominant one in the case of propane cracking in chabazite.

\section{CONCLUSIONS}

Monomolecular cracking of short alkanes on H-ZSM-5 was analyzed by a combination of density functional calculations employing periodic boundary conditions and Monte Carlo simulations in the canonical ensemble with the aim to shed light on the interpretation of measured (apparent) entropies of activation in terms of contributions from adsorption and intrinsic reaction. The results from the Monte Carlo simulations suggest that the entropy of adsorption at reaction temperature is significantly less negative than at temperatures usually employed to measure adsorption parameters, and that its value becomes less negative with increasing temperature. 


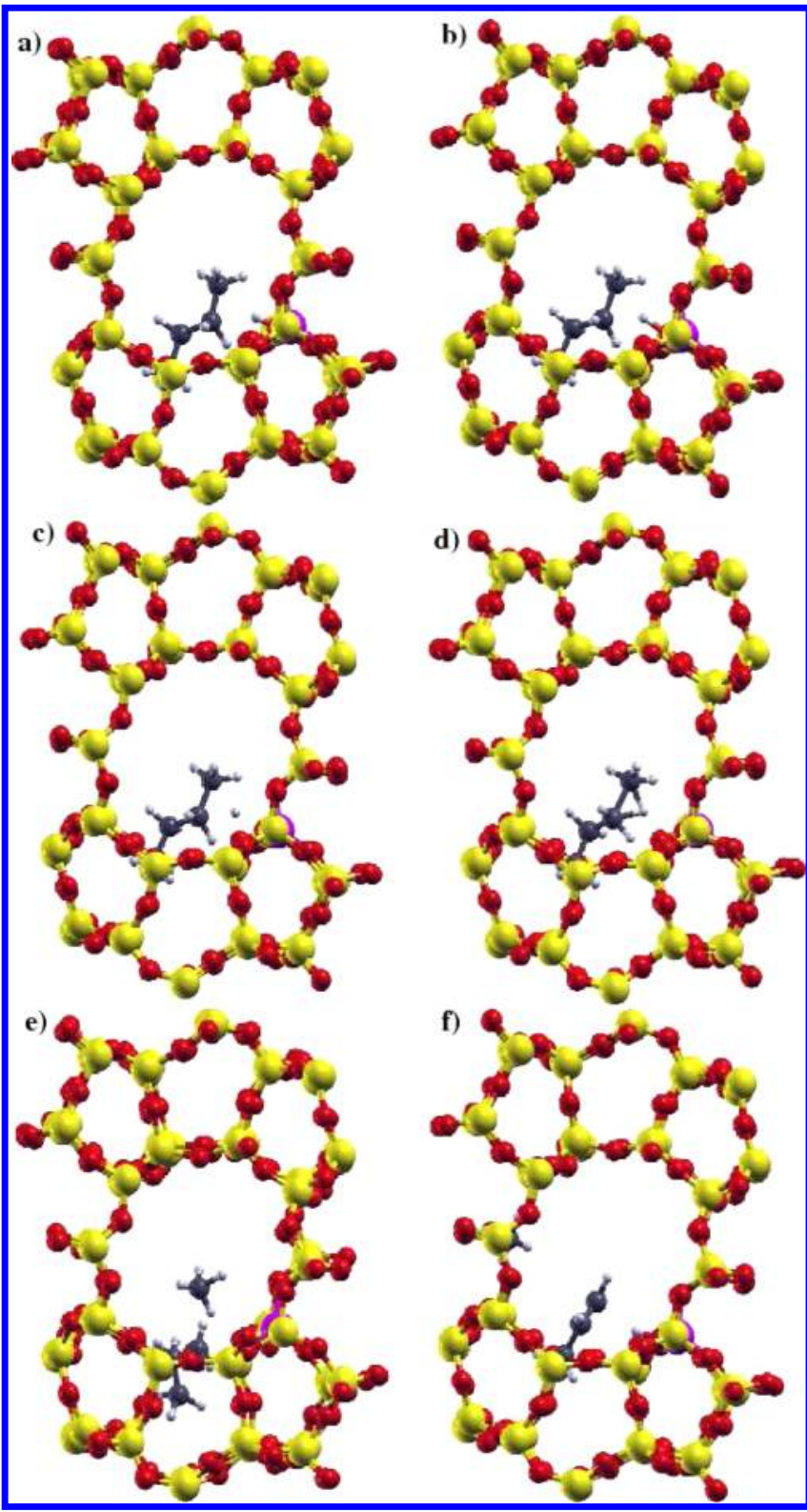

Figure 4. Transition path sampling calculations for butane at $T=800$ K. (a) Butane interacts with the Brønsted acid site via the methyl group. (b) The distance between the butane molecule and the surface decreases. (c) A proton transfers to the $\alpha$ bond. (d) The fivecoordinate alkanium ion is created (TS configuration). (e) The alkanium ion decomposes to the product state. (f) The product state is generated $\left(\mathrm{C}_{3} \mathrm{H}_{6}+\mathrm{CH}_{4}\right)$. Colors: carbon, dark gray; hydrogen, white; oxygen, light red; silicon, light orange; aluminum, purple.

Intrinsic rate parameters obtained from transition state theory show that the intrinsic enthalpy barrier for monomolecular cracking is virtually independent of the alkane chain length, whereas the intrinsic entropy of activation increases with the carbon number. On the basis of the present analysis, we suggest a partitioning of the apparent entropy of activation for propane cracking into a contribution from adsorption of about $-40 \mathrm{~J} /$ $(\mathrm{mol} \mathrm{K})$ and from intrinsic reaction of about $-65 \pm 3 \mathrm{~J} /(\mathrm{mol} /$ $\mathrm{K})$. For longer alkanes the results from Monte Carlo simulations suggest that each additional $\mathrm{CH}_{2}$ group leads to a decrease of the entropy of adsorption of about $-10 \mathrm{~J} /(\mathrm{mol} \mathrm{K})$ and an increase of the intrinsic entropy of reaction of about 6$10 \mathrm{~J} /(\mathrm{mol} \mathrm{K})$. The direct quantification of the latter contribution by means of DFT calculations for alkanes longer than propane requires appropriate averaging over all possible reaction pathways, possibly with the need to go beyond the harmonic transition state theory and will be an important topic for future work.

\section{ASSOCIATED CONTENT}

S Supporting Information

Cartesian coordinates of stationary points optimized on the PBE potential energy surface. This material is available free of charge via the Internet at http://pubs.acs.org.

\section{AUTHOR INFORMATION}

\section{Notes}

The authors declare no competing financial interest.

\section{REFERENCES}

(1) Corma, A. J. Catal. 2003, 216, 298-312.

(2) Horsley, J. A. CHEMTECH 1997, 27, 45-49.

(3) Stöcker, M. Microporous Mesoporous Mater. 2005, 82, 257-292.

(4) Matsuda, T.; Kikuchi, E. Res. Chem. Intermed. 1993, 19, 319-332.

(5) Frei, H. Science 2006, 313, 309-310.

(6) Larsen, S. C. In Environmental Catalysis; Grassian, V. H., Ed.; Taylor \& Francis: Boca Raton, 2005; pp 269-285.

(7) Mignon, P.; Pidko, E. A.; van Santen, R. A.; Geerlings, P.; Schoonheydt, R. A. Chem.-Eur. J. 2008, 14, 5168-5177.

(8) O'Connor, P. Stud. Surf. Sci. Catal. 2007, 166, 227-251.

(9) Swisher, J. A.; Hansen, N.; Maesen, T.; Keil, F. J.; Smit, B.; Bell, A. T. J. Phys. Chem. C 2010, 114, 10229-10239.

(10) Hansen, N.; Brüggemann, T.; Bell, A. T.; Keil, F. J. J. Phys. Chem. C 2008, 112, 15402-15411.

(11) Hansen, N.; Krishna, R.; van Baten, J. M.; Bell, A. T.; Keil, F. J. J. Phys. Chem. C 2009, 113, 235-246.

(12) Hansen, N.; Krishna, R; van Baten, J. M.; Bell, A. T.; Keil, F. J. Chem. Eng. Sci. 2010, 65, 2472-2480.

(13) Bell, A. T.; Head-Gordon, M. Annu. Rev. Chem. Biomol. Eng. 2011, 2, 453-477.

(14) Collins, S. J.; O’Malley, P. J. J. Catal. 1995, 153, 94-99.

(15) Collins, S. J.; O’Malley, P. J. Chem. Phys. Lett. 1995, 246, 555561.

(16) Blaszkowski, S. R.; Nascimento, M. A. C.; van Santen, R. A. J. Phys. Chem. 1996, 100, 3463-3472.

(17) Blaszkowski, S. R.; van Santen, R. A. Top. Catal. 1997, 4, 145156.

(18) Rigby, A. M.; Kramer, G. J.; van Santen, R. A. J. Catal. 1997, 170, $1-10$.

(19) Boronat, M.; Viruela, P.; Corma, A. Phys. Chem. Chem. Phys. 2000, 2, 3327-3333.

(20) Zygmunt, S. A.; Curtiss, L. A.; Zapol, P.; Iton, L. E. J. Phys. Chem. B 2000, 104, 1944-1949.

(21) Zheng, X.; Blowers, P. J. Mol. Catal. A 2005, 229, 77-85.

(22) Zheng, X.; Blowers, P. J. Phys. Chem. A 2005, 109, 1073410741.

(23) Zheng, X.; Blowers, P. J. Phys. Chem. A 2006, 110, 2455-2460.

(24) Van Speybroeck, V.; Van der Mynsbrugge, J.; Vandichel, M.; Hemelsoet, K.; Lesthaeghe, D.; Ghysels, A.; Marin, G. B.; Waroquier, M. J. Am. Chem. Soc. 2011, 133, 888-899.

(25) Gomes, J.; Zimmerman, P. M.; Head-Gordon, M.; Bell, A. T. J. Phys. Chem. C 2012, 116, 15406-15414.

(26) Benco, L.; Bučko, T.; Hafner, J. J. Phys. Chem C 2009, 113, 18807-18816.

(27) Solans-Monfort, X.; Sodupe, M.; Eckert, J. J. Phys. Chem. C 2010, 114, 13926-13934.

(28) Li, G.; Pidko, E. A.; van Santen, R. A.; Feng, Z.; Li, C.; Hensen, E. J. M. J. Catal. 2011, 284, 194-206.

(29) Göltl, F.; Hafner, J. Microporous Mesoporous Mater. [Online early access]. DOI: 10.1016/j.micromeso.2012.04.052. Published Online: 
May 7, 2012. http://www.sciencedirect.com/science/article/pii/ S138718111200279X (accessed July 16, 2012).

(30) Bučko, T.; Benco, L.; Hafner, J.; Ángyán, J. G. J. Catal. 2011, 279, 220-228.

(31) Bhan, A.; Gounder, R.; Macht, J.; Iglesia, E. J. Catal. 2008, 253, 221-224.

(32) Liu, D.; Bhan, A.; Tsapatsis, M.; Al Hashimi, S. ACS Catal. 2011, 1, 7-17.

(33) Gounder, R.; Iglesia, E. J. Am. Chem. Soc. 2009, 131, 19581971.

(34) Gounder, R.; Iglesia, E. Acc. Chem. Res. 2012, 45, 229-238.

(35) Al-majnouni, K. A.; Yun, J. H.; Lobo, R. F. ChemCatChem 2011, $3,1333-1341$.

(36) Haag, W. O.; Dessau, R. M. In Proceedings of The Eighth International Congress on Catalysis, Berlin; Verlag Chemie: Weinheim, 1984; Vol. 2, pp 305-316.

(37) Kresse, G.; Hafner, J. Phys. Rev. B 1993, 47, 558-561.

(38) Kresse, G.; Furthmüller, J. Comput. Mater. Sci. 1996, 6, 15-50.

(39) Kresse, G.; Furthmüller, J. Phys. Rev. B 1996, 54, 11169-11186.

(40) Kresse, G.; Joubert, D. Phys. Rev. B 1999, 59, 1758-1775.

(41) Blöchl, P. E. Phys. Rev. B 1994, 50, 17953-17979.

(42) Hay, D. G.; Jaeger, H.; West, G. W. J. Phys. Chem. 1985, 89, $1070-1072$.

(43) van Koningsveld, H.; Jansen, J. C.; van Bekkum, H. Zeolites 1987, 7, 564-568.

(44) van Koningsveld, H. Acta Crystallogr. 1990, B46, 731-735.

(45) Svelle, S.; Tuma, C.; Rozanska, X.; Kerber, T.; Sauer, J. J. Am. Chem. Soc. 2009, 131, 816-825.

(46) Clark, L. A.; Sierka, M.; Sauer, J. J. Am. Chem. Soc. 2004, 126, 936-947.

(47) Sklenak, S.; Dědeček, J.; Li, C.; Wichterlová, B.; Gábová, V.; Sierka, M.; Sauer, J. Angew. Chem., Int. Ed. 2007, 46, 7286-7289.

(48) Dědeček, J.; Sobalik, Z.; Wichterlová, B. Catal. Rev. Sci. Eng. 2012, 54, 135-223.

(49) Koller, H.; Weiss, M. Top. Curr. Chem. 2012, 306, 189-227.

(50) Mentzen, B. F.; Sacerdote-Peronnet, M. Mater. Res. Bull. 1994, 29, 1341-1348.

(51) Olson, D. H.; Khosrovani, N.; Peters, A. W.; Toby, B. H. J. Phys. Chem. B 2000, 104, 4844-4848.

(52) Heyden, A.; Bell, A. T.; Keil, F. J. J. Chem. Phys. 2005, 123, 224101.

(53) Hammer, B.; Hansen, L. B.; Nørskov, J. K. Phys. Rev. B 1999, 59, $7413-7421$.

(54) Cramer, C. J. Essentials of Computational Chemistry; Wiley: Chichester, U.K., 2002.

(55) De Moor, B. A.; Reyniers, M. F.; Marin, G. B. Phys. Chem. Chem. Phys. 2009, 11, 2939-2958.

(56) De Moor, B. A.; Reyniers, M. F.; Gobin, O. C.; Lercher, J. A.; Marin, G. B. J. Phys. Chem. C 2011, 115, 1204-1219.

(57) De Moor, B. A.; Ghysels, A.; Reyniers, M. F.; Van Speybroeck, V.; Waroquier, M.; Marin, G. B. J. Chem. Theory Comput. 2011, 7, 1090-1101.

(58) Evans, M. G.; Polanyi, M. Trans. Faraday Soc. 1935, 31, 875894.

(59) Eyring, H. J. Chem. Phys. 1935, 3, 107-115.

(60) McQuarrie, D. A. Statistical Mechanics, 1st ed.; Harper Collins: New York, 1973.

(61) Bučko, T.; Benco, L.; Dubay, O.; Dellago, C.; Hafner, J. J. Chem. Phys. 2009, 131, 214508.

(62) Bučko, T.; Hafner, J. J. Phys.: Condens. Matter 2010, 22, 384201.

(63) Wesolowski, T. A.; Parisel, O.; Ellinger, Y.; Weber, J. J. Phys. Chem. A 1997, 101, 7818-7825.

(64) Zhang, Y.; Pan, W.; Yang, W. J. Chem. Phys. 1997, 107, 79217925.

(65) Gritsenko, O. V.; Ensing, B.; Schipper, P. R. T.; Baerends, E. J. J. Phys. Chem. A 2000, 104, 8558-8565.

(66) Porezag, D.; Pederson, M. R. J. Chem. Phys. 1995, 102, 93459349.

(67) Perdew, J. P.; Zunger, A. Phys. Rev. B 1981, 23, 5048-5079.
(68) Kümmel, S.; Kronik, L. Rev. Mod. Phys. 2008, 80, 3-60.

(69) Furche, F. Phys. Rev. B 2001, 64, 195120.

(70) Harl, J.; Kresse, G. Phys. Rev. B 2008, 77, 045136.

(71) Dion, M.; Rydberg, H.; Schröder, E.; Langreth, D. C.; Lundqvist, B. I. Phys. Rev. Lett. 2004, 92, 246401.

(72) Grimme, S. J. Comput. Chem. 2004, 25, 1463-1473.

(73) Grimme, S. J. Comput. Chem. 2006, 27, 1787-1799.

(74) Grimme, S.; Antony, J.; Ehrlich, S.; Krieg, H. J. Chem. Phys. 2010, 132, 154104.

(75) Tkatchenko, A.; Scheffler, M. Phys. Rev. Lett. 2009, 102, 073005.

(76) Jurecka, P.; Cerny, J.; Hobza, P.; Salahub, D. R. J. Comput. Chem. 2007, 28, 555-569.

(77) Ortmann, F.; Bechstedt, F.; Schmidt, W. G. Phys. Rev. B 2006, 73, 205101.

(78) Zimmerli, U.; Parrinello, M.; Koumoutsakos, P. J. Chem. Phys. 2004, 120, 2693-2699.

(79) Wu, Q.; Yang, W. J. Chem. Phys. 2002, 116, 515-524.

(80) Kerber, T.; Sierka, M.; Sauer, J. J. Comput. Chem. 2008, 29, 2088-2097.

(81) Cheng, L.; Curtiss, L. A.; Assary, R. S.; Greeley, J.; Kerber, T.; Sauer, J. J. Phys. Chem. C 2011, 115, 21785-21790.

(82) Hansen, N.; Kerber, T.; Sauer, J.; Bell, A. T.; Keil, F. J. J. Am. Chem. Soc. 2010, 132, 11525-11538.

(83) Lo, C. S.; Radhakrishnan, R.; Trout, B. L. Catal. Today 2005, $105,93-105$.

(84) Chandler, D. In Classical and Quantum Dynamics in Condensed Phase Simulations; Berne, B. J., Ciccotti, G., Coker, D. F., Eds.; World Scientific: Singapore, 1998; pp 51-66.

(85) Dellago, C.; Bolhuis, P. G.; Csajka, F. S.; Chandler, D. J. Chem. Phys. 1998, 108, 1964-1977.

(86) Dellago, C.; Bolhuis, P. G.; Chandler, D. J. Chem. Phys. 1998, $108,9236-9245$.

(87) Bolhuis, P. G.; Dellago, C.; Chandler, D. Faraday Discuss. 1998, 110, 421-436.

(88) Dellago, C.; Bolhuis, P. G.; Chandler, D. J. Chem. Phys. 1999, $110,6617-6625$.

(89) Bolhuis, P. G.; Dellago, C.; Chandler, D. Proc. Natl. Acad. Sci. U. S. A. 2000, 97, 5877-5882.

(90) Dellago, C.; Bolhuis, P. G.; Geissler, P. L. Adv. Chem. Phys. 2002, 123, 1-78.

(91) Bolhuis, P. G.; Chandler, D.; Dellago, C.; Geissler, P. L. Annu. Rev. Phys. Chem. 2002, 53, 291-318.

(92) E, W.; Vanden-Eijnden, E. Annu. Rev. Phys. Chem. 2010, 61, 391-420.

(93) Widom, B. J. Chem. Phys. 1963, 39, 2808-2812.

(94) Dubbeldam, D.; Calero, S.; Vlugt, T. J. H.; Krishna, R.; Maesen, T. L. M.; Smit, B. J. Phys. Chem. B 2004, 108, 12301-12313.

(95) Dubbeldam, D.; Calero, S.; Vlugt, T. J. H.; Krishna, R.; Maesen, T. L. M.; Beerdsen, E.; Smit, B. Phys. Rev. Lett. 2004, 93, 088302.

(96) Eder, F.; Stockenhuber, M.; Lercher, J. A. J. Phys. Chem. B 1997, 101, 5414-5419.

(97) Eder, F.; Lercher, J. A. Zeolites 1997, 18, 75-81.

(98) Arik, I. C.; Denayer, J. F.; Baron, G. V. Microporous Mesoporous Mater. 2003, 60, 111-124.

(99) Frenkel, D.; Smit, B. Understanding Molecular Simulations: From Algorithms to Applications, 2nd ed.; Academic Press: San Diego, 2002. (100) Smit, B.; Maesen, T. L. M. Chem. Rev. 2008, 108, 4125-4184.

(101) Narbeshuber, T. F.; Vinek, H.; Lercher, J. A. J. Catal. 1995, $157,388-395$.

(102) Sun, M. S.; Shah, D. B.; Xu, H. H.; Talu, O. J. Phys. Chem. B 1998, 102, 1466-1473.

(103) Denayer, J. F.; Souverijns, W.; Jacobs, P. A.; Martens, J. A.; Baron, G. V. J. Phys. Chem. B 1998, 102, 4588-4597.

(104) Keil, F. J. Chem. Ing. Tech. 2011, 83, 1-24.

(105) Xu, B.; Sievers, C.; Hong, S. B.; Prins, R.; van Bokhoven, J. A. J. Catal. 2006, 244, 163-168.

(106) Zhao, Y.; Truhlar, D. G. J. Phys. Chem. A 2005, 109, 56565667.

(107) Zhao, Y.; Truhlar, D. G. Acc. Chem. Res. 2008, 41, 157-167. 
(108) Tuma, C.; Sauer, J. Phys. Chem. Chem. Phys. 2006, 8, 39553965.

(109) Tuma, C.; Kerber, T.; Sauer, J. Angew. Chem., Int. Ed. 2010, 49, $4678-4680$.

(110) Zimmerman, P. M.; Head-Gordon, M.; Bell, A. T. J. Chem. Theory Comput. 2011, 7, 1695-1703.

(111) Manthe, U. Mol. Phys. 2011, 109, 1415-1426.

(112) Maesen, T. L. M.; Beerdsen, E.; Calero, S.; Dubbeldam, D.; Smit, B J. Catal. 2006, 237, 278-290.

(113) Bakker, W. J. W.; van den Broeke, L. J. P.; Kapteijn, F.; Moulijn, J. A. AIChE J. 1997, 43, 2203-2214.

(114) Zhu, W.; van den Graaf, J. M.; van den Broeke, L. J. P.; Kapteijn, F.; Moulijn, J. A. Ind. Eng. Chem. Res. 1998, 37, 1934-1942.

(115) Myers, A. L. Colloids Surf., A 2004, 241, 9-14.

(116) Maginn, E. J.; Bell, A. T.; Theodorou, D. N. J. Phys. Chem. 1995, 99, 2057-2079.

(117) Vlugt, T. J. H.; Krishna, R.; Smit, B. J. Phys. Chem. B 1999, 103, 1102-1118.

(118) Millot, B.; Methivier, A.; Jobic, H. J. Phys. Chem. B 1998, 102, 3210-3215.

(119) Makowski, W.; Majda, D. J. Porous Mater. 2007, 14, 27-35.

(120) Makowski, W.; Gil, B.; Majda, D. Catal. Lett. 2008, 120, 154160.

(121) Majda, D.; Makowski, W. J. Therm. Anal. Calorim. 2010, 101, 519-526.

(122) Barrer, R. M. Zeolites and Clay Minerals as Sorbents and Molecular Sieves; Academic Press: New York, 1978.

(123) Liu, Y. J. Chem. Eng. Data 2009, 54, 1981-1985.

(124) Göltl, F.; Grüneis, A.; Bučko, T.; Hafner, J. J. Chem. Phys. 2012, 137, 114111.

(125) Moss, G. P.; Smith, P. A. S.; Tavernier, T. Pure Appl. Chem. 1995, 67, 1307-1375. 